\title{
Adapting New Space System Designs into Existing Ground Infrastructure
}

\author{
Hector N. Delgado ${ }^{*}$ and Carey M. McCleskey ${ }^{\dagger}$ \\ NASA John F. Kennedy Space Center, Florida, 32899 USA
}

\begin{abstract}
As routine space operations extend beyond earth orbit, the ability for ground infrastructures to take on new launch vehicle systems and a more complex suite of spacecraft and payloads has become a new challenge. The U.S. Vision for Space Exploration and its Constellation Program provides opportunities for our space operations community to meet this challenge. Presently, as new flight and ground systems add to the overall groundbased and space-based capabilities for NASA and its international partners, specific choices are being made as to what to abandon, what to retain, as well as what to build new. The total ground and space-based infrastructure must support a long-term, sustainable operation after it is all constructed, deployed, and activated. This paper addresses key areas of engineering concern during conceptual design, development, and routine operations, with a particular focus on: (1) legacy system reusability, (2) system supportability attributes and operations characteristics, (3) ground systems design trades and criteria, and (4) technology application survey. Each key area explored weighs the merits of reusability of the infrastructure in terms of: engineering analysis methods and techniques; top-level facility, systems, and equipment design criteria; and some suggested methods for making the operational system attributes (the "-ilities") highly visible to the design teams and decisionmakers throughout the design process.
\end{abstract}

\section{Introduction}

A EROSPACE ground systems are historically large, complex, and expensive systems which must perform safely and efficiently through very difficult operating environments. Additionally, investments in these systems must last for a long time with as low recurring maintenance as possible. With this background, some of the existing ground systems and infrastructure at the Kennedy Space Center go back to the Apollo program. With reasonable maintenance and upgrades they should help us get back to the Moon and beyond.

The post-Shuttle space flight architecture has been defined in the Exploration Systems Architecture Study (ESAS) of 2005. ${ }^{1}$ The principle policy documents pertinent to this architecture are President Bush's January 2005 speech outlining the Vision for Space Exploration and the NASA Authorization Act of 2005, which details statutory requirements for Shuttle transition: to use to the fullest extent possible, the personnel, assets, capabilities and infrastructure of the Space Shuttle Program in the development of the new program. ${ }^{2,3}$

Much of the existing ground systems and infrastructure at the Kennedy Space Center have remained in place and endured since the initial Apollo program investment. As part of the transition from the Space Shuttle program to the new architecture, the Kennedy Space Center (KSC), along with its Constellation partners, has embarked on a system-by-system assessment throughout the KSC infrastructure. This assessment approach compares the needs of the new architecture and new requirements with the existing systems and infrastructures. It then identifies which facilities, facility systems, and distributed services need to be modified, upgraded, designed new, or closed down, because they are no longer needed to support the Constellation program. With reasonable maintenance and upgrades, much of the existing mobile launch infrastructure supports the policy and statutory requirements to get us back to the Moon and beyond.

\footnotetext{
* Chief Engineer, Engineering Development Directorate, Design and Development Office, Kennedy Space Center/NE-D.

${ }^{\dagger}$ Technical Manager, Engineering Development Directorate, Systems Engineering Branch, John F. Kennedy Space Center/NE-D2, Senior AIAA Member.
}

American Institute of Aeronautics and Astronautics 


\section{Apollo-Saturn V Ground Infrastructure}

This section reviews the function and characteristics of NASA's Kennedy Space Center ground infrastructure in support of the Apollo Program. While not intended as a thorough accounting of the launch facilities and equipment, the major elements are described with particular emphasis on those items that would evolve over time following the Apollo-Saturn era.

\section{A. Apollo-Saturn V Ground Infrastructure Mission and Purpose}

The supporting ground infrastructure for Project Apollo evolved very quickly in the early years of the 1960s. The first Saturn vehicles, and their launch systems at Cape Canaveral, were conceived prior to the national lunar landing program for research and development purposes. For example, NASA's intent (in a 1960 NASA Headquarters schedule) was to progress towards as many as fifty (50) Saturn C-1 and C-2 launches between 1965 and 1970 - with twenty (20) of those devoted to a tenuous new project called Apollo. To support such a pace, new launch architectures, with greater launch capacity than Complexes 34 and 37, were needed. Further, when President Kennedy on 25 May 1961 called for a manned landing on the Moon before 1970, the scale of the launch vehicle architectures increased tremendously from the relatively smaller Saturn concepts previously envisioned. ${ }^{4}$

The purpose of the new ground architecture was made clear with the U.S. commitment to land a man on the Moon: a new, larger-scale, and more efficient launch complex would be built to routinely take humans into space, on to the Moon and beyond, so that the nation could have a clearly leading role in space exploration. The search for a specific design of the new launch complex was identified as a "crucial item" by NASA Headquarters and a comprehensive four-week study ensued leading to a 460-page technical survey delivered on 31 July $1961 .{ }^{5}$

\section{B. Apollo-Saturn V Ground Architectural Approach}

To meet the needs of the routine and more efficient Saturn launch operations, NASA design engineers at the Launch Operations Directorate (LOD) in Cape Canaveral, and at its headquarters in Huntsville, Alabama, began serious exploration of a large-scale assembly, transfer, and launch concept. This concept was a departure from typical stack-on-pad approaches and moved to one of mobile launch. Previously, each space vehicle element was sent to its launching pad where the entire space vehicle (both its launch vehicle elements and its spacecraft or payload) was mated and the necessary ancillary systems assembled onto the vehicle. All troubleshooting, calibrations, and subsystems servicing was accomplished with large gantries co-located with (or near) a fixed launch pad that were exposed to the elements for months-long campaigns. ${ }^{6}$

The basic characteristics of the new Saturn mobile launch concept was defined in what became known as the "Debus-Davis Report." ${ }^{7,8}$ It was to have a facility with a set of large-scale assembly bays preparing and testing the space vehicle on a mobile launcher/transporter, followed by a transfer of the combined Saturn-Apollo/Mobile Launcher stack to its launch pad for a relatively brief pre-flight checkout and launch countdown. In this way the utilization of the launching pad (and, therefore, the whole system) could be fed by a set of parallel vehicle assembly processes. Additionally, both the flight systems and the launch team would be protected from wind, rain, and lightning for the assembly and test operations. It also had the advantage of being able to send the vehicle back to the protected assembly facility in case of hurricanes. ${ }^{9,10}$

The original intent was to cut the pad stay time from two months to ten days. Otherwise, planners were faced with constructing as many as ten separate launch pads to meet the payload delivery demands_projected to reach as many as fifty Saturn launches per year. ${ }^{11}$

\section{Apollo-Saturn V Ground System Configuration}

The NASA presence at Cape Canaveral grew after President Kennedy's commitment to go the Moon. Land was purchased by the government adjacent to the existing launch facilities. The utilization of this newly acquired land was divided for two distinct purposes. The first was to build the facilities needed to bring the mobile launch concept to reality. The second area of land was used to construct an industrial area to support and enable the operations at the new Moonport.

\section{Launch Complex 39 Configuration}

The primary elements of the launch complex were all designed with extendable capabilities. They included: a Vehicle Assembly Building (VAB) with four initial high bays, extendible to the north; a set of Mobile Launchers with an umbilical tower; an adjacent Launch Control Center (LCC), with multiple firing rooms; and a set of launch pads, initially constructed with Pads 39A and 39B, but with footprints extended for a Pad 39C if necessary, drawn up on the master plans. In addition to these primary facilities were enabling support facilities and connecting services. These included: a separate launch equipment shop (LES); high pressure gas facility and distribution 
system; ordnance storage facility; a crawler way connecting the assembly building to the launch pads; and a service and park site for the crawler, mobile launchers, and eventually, a separate mobile service structure.

Vehicle Assembly Building (VAB) Characteristics-With many different configurations of the launch vehicle still under trade, the overall height of the vertical assembly facility needed to be set. A design parameter known as hook height defined the height of the facility. The hook height is defined not only by the vertical height of the launch vehicle, but also by the height from the floor of the facility to the base of the launch vehicle on its mobile launcher platform, and by the practical height a crane hook would need to attain to stack the top-most element of the launch vehicle and any other potential ancillary lifts required of the vehicle stacking operations. Accounting for various Saturn and Nova concepts under trade, the VAB height was set at $160 \mathrm{~m}(520 \mathrm{ft})$. Each assembly bay was positioned on either side of a long floor-to-ceiling transfer aisle, in which each space vehicle stage or element would be received and hoisted onto the appropriate mobile launcher via large $227 \mathrm{mt}$ (250 ton) bridge cranes. Additionally, there would be a smaller $159 \mathrm{mt}$ (175 ton) bridge crane that would traverse the length of the transfer aisle at a lower height to aid in the handling operations.

With the general layout of the VAB and the Apollo/Saturn space vehicle in hand, the next step was outfitting the facility to match the final configuration of the Saturn launch vehicle and the Apollo spacecraft (see Fig. 1). Once the Apollo-Saturn $\mathrm{V}$ vehicle configuration was established as the configuration for the flight systems, the primary adaptation in the VAB was a means for the workers to access the vehicle for assembly, servicing, and test operations. Each vehicle integration high bay was outfitted with a symmetric set of horizontally-translating (or extensible) work platforms (see Figs. 1 and 2). The main thing to note is that the cross-section of the flight system at various heights and the required servicing, access doors, umbilicals, and flight panels requiring manual labor, are all important flight-to-ground system design details that go into the design of this important facility element, i.e., the extensible high bay work platforms. Also to be accounted for in the design of these platforms was the amount and size of the ground support equipment, both fixed and mobile, that could be put on these platforms due to platform structural loading constraints. The simpler the flight system design was, the simpler the platform design would be.

Mobile Launcher (ML) Characteristics-As with the VAB, the Mobile Launcher and the Saturn-Apollo space vehicle design had to be performed simultaneously and had to be physically and functionally compatible. Not only was access in the VAB accounted for, but also access at the Pad. While Pad access was to be kept at a minimum, it nonetheless had to be taken into account. Also, design of launch umbilicals was a challenge, many of them requiring near-instantaneous release at liftoff, known as T-0 umbilicals (see Fig. 3). In addition to its function as a structural support for the space vehicle, the ML also provided the propellants, service fluids, gasses, electrical power, control and data cables and networks, as well as radio frequency (rf) antenna and receiver equipment. At 5,715 mt $(12,600,000 \mathrm{lbs})$ with an un-fueled vehicle, the Mobile Launcher was a massive and highly complex device.

Since this was a transportable structure to be carried by one of two crawler transporters, the total weight had to be managed during the design. This included accommodating central high speed elevators, as well as wrap-around stairway structures for manual access and emergency egress. These and other parameters sized the structure and its overall mass characteristics.

Emergency egress for the flight crew was accomplished via high speed elevator and slide wire baskets rigged to the launch pad once the ML/Apollo-Saturn stack arrived at the Pad. Lightning protection was provided through a mast that was rotated to the vertical position once clear of the VAB doors on its way to the Pad.

Crawler Transporter (C/T) Characteristics-To carry the MLs to and from the launch pads, two massive doubletracked crawler transporters were designed and built. The crawler was also used to carry the equally massive Mobile Service Structure that was later required for on-pad Apollo spacecraft servicing. The technology behind these vehicles was derived from the mining industry. They were driven by 16 traction motors powered by four 1,000 kw generators, all in turn driven by two diesel engines. In addition, a set of jacking, leveling, and steering equipment was designed so that the entire stack could travel across the crawler way and safely traverse the $5 \%$ incline up the Pad apron in a level attitude. Its maximum speed was $1.6 \mathrm{~km} / \mathrm{hr}$ loaded, and $3.2 \mathrm{~km} / \mathrm{hr}$ unloaded, requiring a 7-hour trip between the VAB and the Pad with the combined ML/launch vehicle load.

Launch Control Center (LCC) Characteristics-Command, control, and communication with the flight and ground systems was accomplished through a centralized, four-story control center. More than just a set of remote monitoring consoles, this "nerve center" provided a means for the workforce to plan and execute the thousands of tasks (both automated and manually executed) required to successfully integrate, test, and launch the Apollo missions. 
In the facility were three firing rooms outfitted with a myriad of electronic command and control consoles that not only monitored the flight system telemetry during launch processing, but also remotely controlled highly dangerous propellant loading procedures that are too dangerous for local personnel to perform. The consoles were provided separately, often by different suppliers and technical disciplines. Many consoles were unique and the process of powering up and operating a console was often different amongst subsystems and stages. The facility also controlled high pressure gas networks, a network of literally scores and scores of operational voice and video monitoring equipment throughout the launch complex, data storage equipment, and data review rooms with the strip chart recorders of the era. Process planning, scheduling, and control were accomplished in a fourth "firing room" specially outfitted for this function. Centralizing the networks and control of the entire complex, and removing it from the blast danger area of the launch pad was a revolutionary idea at the time that eliminated the need for designing bunker-type blockhouses, previously located near the launching point (see Fig. 4).

Launch Pad Characteristics-The launch pad was free of major permanent, elevated steel structures. One of the main features of Launch Pads 39A and 39B were the main fuel and oxidizer propellant storage areas (LOX, LH2, and RP-1). Of particular importance to the evolution of this launch pad was the major investment in large-scale liquid oxygen and liquid hydrogen storage spheres, conditioning equipment, and propellant transfer lines. This cryo fuel farm became an important asset as the nation's large-scale human spaceflight programs evolved.

Also, a critical investment was made in constructing the angular Pad apron and its crawler ramp, including a special incline with a 5\% grade to support the transfer of the Mobile Launcher. In designing the Pad, the flame trench height $(13 \mathrm{~m})$ was defined by the exhaust plume characteristics of the Saturn V launch vehicle, and the flame trench width (18 m) was defined by the Mobile Launcher/Crawler dimensions straddling over the trench (Fig. 5). Additionally, a $635 \mathrm{mt}$ movable flame deflector was created with special thermal protection materials.

Mobile Service Structure (MSS) Characteristics - Late requirements during the design phase for the Apollo Command/Service Module (C/SM) and the Lunar Module (LM) created the need for an additional service structure at the Pad for final spacecraft toxic propellant servicing and final ordnance installations unreachable from the Mobile Launcher side of the vehicle. The result was the creation of a massive (4,760 mt and $125 \mathrm{~m}$ high) steel Mobile Service Structure, or MSS (see Fig. 6).

\section{KSC Industrial Area Configuration}

The Industrial Area of NASA's launch center consisted of: office buildings; supply, shipping, and receiving areas; warehouses; a Manned Spacecraft Operations Building for checkout and final assembly of the Apollo spacecraft, and for astronaut operations; a Flight Crew Training Building; various hazardous spacecraft servicing facilities; a medical facility, a post office, and a fire station. We'll cover a few of these as they relate to Industrial Area evolution through the Shuttle and Constellation programs.

Operations and Checkout (O\&C) Building Characteristics-The various spacecraft modules that made up the Apollo spacecraft all arrived at the O\&C for checkout, pre-stacking servicing, and element mating. This included checkout and assembly of the Command Module, the Service Module, the ascent and descent stages of the Lunar Module, and the Spacecraft/Launch Vehicle Adapter (or SLA). The major characteristics of this facility were: a high bay with overhead bridge crane set at $36 \mathrm{~m}$ hook height; a contiguous low bay at $15 \mathrm{~m}$ hook height for spacecraft element receiving and checkout; a below-floor-level equipment area; service and assembly stands; and two large altitude chambers. These altitude chambers served several purposes, including vacuum checks of hatches, vacuum compatibility checks of crew cabins, and astronaut flight crew training in their pressure suits. Additionally, a separate set of Automated Checkout Equipment, or ACE, was placed in nearby rooms, which were composed of remote consoles for the monitoring of the Apollo spacecraft hardware throughout the launch process, even while at the launch Pad.

Fluid Test Complex Characteristics — Set apart from the offices and laboratories of the Industrial Area were various facilities, collectively known as the Fluid Test Complex (and familiarly known as the south 40 complex). Included were facilities where toxic fluid and hazardous cryogenic fluid operations were intended to occur. Additionally, spacecraft ordnance storage and test ranges for the lunar landing radar were carved out for the area. The special fluid test facilities provided means for explosion control, vapor exhaust, and remote monitoring of hazardous loading and handling operations.

\section{Apollo-Saturn V Ground Infrastructure Evolution}

The Apollo program went through several mission evolutions. Along with those evolutions, the launch center also went through some minor changes. The missions evolved from initial lunar landing capability missions to more 
advanced lunar landing missions. An Apollo Applications Program evolved into the nation's first man-tended space station - the Skylab missions, which utilized an evolved Saturn V for both the laboratory and its launch vehicle. Following the changes at the launch site for the Skylab program, the Apollo-Soyuz Test Project (ASTP) was also performed, ending the Apollo program in 1975.

Mobile Launcher Evolution-The first Mobile Launcher (ML-1) was redesigned to accommodate the crew launch vehicle for the Skylab program: the older, smaller Saturn-1B, once used for precursor Apollo development flights, and which had previously flown from the mothballed Launch Complex 37. Since the upper stage and spacecraft were identical between the Saturn-1B and the Saturn V, the Mobile Launcher was compatible from the third stage up. A launch stand adapter was developed, known as the milk stool, to provide the spacing difference (see Fig. 7). Also modified were the servicing, umbilical, and command and control systems for the Saturn 1B stage.

\section{E. Apollo-Saturn V Ground Infrastructure Outcome \\ 1. Design and Development Outcome}

The design and development outcome of the Apollo Program was the establishment of NASA's Launch Complex 39 mobile launch infrastructure, including two heavy lift launch pads, a massive Vehicle Assembly Building (VAB), and a Launch Control Center (LCC). Additionally, the enabling infrastructure established for human spaceflight and centralized in KSC's new Industrial Area, allowed for NASA's continued evolution without scrapping this infrastructure and starting over. More importantly, the design engineering practices and know-how was captured in a work force that would continue its work as the goal of routine space flight was realized in the development of the Space Shuttle.

2. Operational Outcome

While the original flight rate projections that were present at the initiation of the development of Launch Complex 39 did not materialize, the outcome was two unmanned test flights of the Saturn V, followed by ten more successful Apollo-Saturn V launches-with all but one (the Apollo 9 mission) having the Moon as its destination. The maximum flight rate attained for the launch complex occurred during 1969 with four Apollo-Saturn V launches occurring, settling to two flights per year before the lunar landing program was ended. The Apollo Program came to an end in 1972, less than ten years after the infrastructure, intended for support of long-term national space exploration, had been created.

In summary, a Moonport had been established with the capability to repeatedly launch humans to the Moon. The flexibility and utility of the mobile launch infrastructure was demonstrated with the Skylab and ASTP programsand the stage was now set for the next set of human space flight objectives.

\section{Space Shuttle Ground Infrastructure}

This section reviews the function and characteristics of NASA's Kennedy Space Center in support of the Space Shuttle Program. Again, while not intended as a thorough accounting of the launch facilities and equipment, the major elements are described with particular emphasis on those items that evolved from the Apollo-Saturn era to support the objective of routine, affordable, and sustainable human space flight to and from low earth orbit (LEO).

\section{A. Space Shuttle Ground Infrastructure Mission and Purpose}

The Apollo-era ground infrastructure at the Kennedy Space Center was promoted for reuse in support of the Space Shuttle Program goals. The Center's infrastructure provided an efficient and affordable means to attain the capability for routine space flight to and from earth orbit with a reusable space vehicle; initially a two-stage, fully reusable concept, and later, the familiar partially reusable Space Shuttle design we know today. The 1969 Space Task Group envisioned a reusable fleet of Space vehicles that could then perform the missions at a rate necessary to assemble a permanent space station in LEO. ${ }^{12}$

The purpose for the ground infrastructure, then, was to provide both a launch and a landing site - one that would transform the Moonport of the 1960s into a routine Spaceport capable enough and affordable enough to execute launches and landings into the twenty-first century. The program requirement was to provide a set of flight and ground equipment compatible with routine launches executable in 160 serial work hours, or about 40 to 60 flights per year.

\section{B. Space Shuttle Ground Architectural Approach}

Initially, the ground architectural approach was to use Saturn-Apollo mobile launch towers for the two-stage fully reusable design. ${ }^{13}$ However, as with most programs, the flight system architecture evolved over time. In the case of the Space Shuttle, the flight system became a partially reusable design with a reusable winged Orbiter, dual 
recoverable segmented solid rocket boosters, and an expendable external cryogenic propellant tank. The ground architectural approach also evolved from the Saturn-Apollo approach of a mobile launch umbilical tower, to one of a clean mobile launch platform with tower structures removed to permanent, pad-fixed structures. This included a fixed service structure for the launch vehicle functions and a rotating service structure, as well, once the requirement for a large payload bay emerged in the design for payload installation and change-out (see Fig. 9).

\section{Space Shuttle Ground System Configuration}

For the Space Shuttle Program the requirements were to avoid massive ground infrastructure investments and use existing national investments in space launch infrastructure. As such, design proceeded with the Launch Complex 39 mobile launch concept in mind. Specific differences in Launch Complex 39 infrastructure for the Space Shuttle are discussed below.

Vehicle Assembly Building (VAB) Characteristics-The Vehicle Assembly Building itself was sound and the only major adaptation to be made was with the extensible work platforms, which needed to be modified to conform to the complex outer mold line of the integrated Space Shuttle Vehicle. The other complicating factor was the additional hazard of handling segmented solid propellant motors with open grain in the facility. Hazard analyses, personnel restrictions, and operational constraints were imposed so as to allow this concept to be safely implemented.

Additionally, with four high bays available, advantage was taken in the utilization of these available assets. The two east-facing high bays became the Space Shuttle Vehicle integration cells. The other high bays were used for storage of the large external tanks and also used as surge storage for the growing fleet of Orbiters and even as a hurricane safe haven for a completed stack rolled back from the launch pad.

Mobile Launcher (ML) Characteristics-The mobile launchers were reused in the Space Shuttle configuration. However, the design approach was to eliminate swing arm type T-0 umbilicals, in favor of consolidated T-0 service masts, fixed and protected on the launcher deck, and connected to the aft compartment of the Orbiter vehicle. The tower was eliminated from the Mobile Launcher to help lighten the transfer load with the heavy solid boosters. The tower function was transferred to fixed structures on the Pad surface. The result was a new Space Shuttle Mobile Launch Platform (MLP) with no attached tower-hence the name change from "Mobile Launcher."

Crawler Transporter (C/T) Characteristics-With the transfer load alleviated for a clean launcher approach, no new transporters were required. Some upgrades to the crawler's control were made and the life extended for these important national investments.

Launch Control Center (LCC) Characteristics - The primary change in the Launch Control Center was in standardizing and automating the firing room equipment with what was then advanced, digital control systems. Advantage was taken of the new electronics and software revolution emerging in the 1970s, with rapid advancements being made in data storage technologies, integrated circuits, microprocessors, and so forth. A standardized test and checkout software language was developed and customized for launch systems engineers, referred to as Ground Oriented Aerospace Language, or GOAL. A set of standard consoles were designed, derived from hardware casings used during the Apollo era. Each console would be standard in design and loaded with unique software applications for the function being performed. If a console failed, a backup could be loaded and prepared in the time it took for the operators to physically move to the backup console. For the few time-critical safety functions, special control logic was designed, and even hard wire circuits that bypassed the software functions were designed in. Special data storage areas were placed in the LCC for engineers to review data post-test and in real time. Three firing rooms were initially re-outfitted with this new Launch Processing System (LPS), but in practice only two were used for the flight rates that emerged. The other firing room became a software improvement and development firing room, and with the new flexibility, was also used for management oversight during launch countdown operations. ${ }^{14}$

Launch Pad Characteristics-As mentioned, the Pad underwent several modifications to accommodate the Space Shuttle. Before addressing those, it is important to note what remained intact. The previous investment in the cryogenic storage and distribution systems, i.e., the cryo fuel farm, was sufficient in capability to support Shuttle operations, thus saving a tremendous amount of design effort, development and construction time, and expense. ${ }^{15}$

A shorter service structure was fixed to the Pad to provide launch crew and flight crew access to the integrated Space Shuttle Vehicle. A rotating service structure hinged to the fixed tower swung on a railed track around and over the flame trench to wrap around the Orbiter vehicle payload bay and allow for vertical insertion of payloads at the Pad. Additionally, a hydrogen vent arm was required due to the placement of the hydrogen tank and the venting approach used in the external tank. The slide wire emergency egress approach was also used and became more effective with the crew cabin lowered in height relative to the towering Saturn configuration. The RP-1 fuel storage 
area was no longer needed. Due to the anticipated high flight rates, the servicing of toxic propellants was permanently fixed to the Pad area in fuel and oxidizer hypergol fuel farms.

Mobile Service Structure Characteristics-The mobile service structure was eliminated in favor of the rotating service structure and the fixed hypergolic fuel farms.

Orbiter Processing Facility (OPF) Characteristics-A separate set of hangars capable of horizontal processing of the Orbiters were created. Ultimately, three were constructed for the fleet. Additionally, it became necessary to create a set of auxiliary facilities, such as: a mate/demate device at the landing field for use with the 747 Shuttle Carrier Aircraft (SCA); a dedicated thermal protection system (TPS) shop; a dedicated shop for overhaul and inspection of the reusable Space Shuttle Main Engines (SSMEs); a wheel and tire shop, and dedicated Orbiter logistics facilities.

\section{KSC Industrial Area Configuration}

The Industrial Area, too, underwent some changes in support of the Shuttle Program.

Operations and Checkout (O\&C) Building Characteristics - The newly organized European Space Agency (ESA) contributed a modular, reusable Spacelab to take full advantage of the Space Shuttle's capabilities to return and reuse large payloads. The O\&C building was re-outfitted to manage the assembly and reconfiguration of these payloads.

Hypergolic Maintenance Facility (HMF) Characteristics - The design of the Orbiter vehicle included modular, detachable reaction control and orbital maneuvering pods so that separate maintenance of these toxic, hazardous systems could occur away from the rest of the Orbiter vehicle and its work crew. This created the need to convert a portion of the old fluid test complex into a Hypergolic Maintenance Facility, or HMF. This facility had the necessary toxic fuel and oxidizer storage and disposal capability, emergency exhaust systems, and spill handling equipment. It also used a localized LPS control room, but isolated from the hazardous operations in the maintenance bay. Due to the challenges in reusing hypergolic systems, creation of the HMF turned out to be a wise decision.

Launch Equipment Test Facility (LETF) Characteristics - To avoid the expensive qualification of separate umbilical devices as encountered in the Apollo program, a launch equipment test facility was created to develop and certify critical Pad and MLP equipment. Specifically, the hydrogen vent arm, the new Tail Service Masts (TSMs), and their complex T-0 umbilical plates. When the time came to load and operate the Shuttle stack for the first time, a great deal of risk had already been retired through this investment.

\section{Space Shuttle Ground Infrastructure Outcome}

\section{Design and Development Outcome}

The result of the Space Shuttle design and development effort was an expansion of facility capabilities to include not only launch, but also the ground infrastructure needed for landing, reusable element retrieval, recovery, and refurbishment. The design and development proceeded on a schedule that was compatible with the development of the flight systems, such that by the time the system was ready to receive flight hardware in 1979, the facility infrastructure was ready; and by the time the flight systems were ready for launch in 1981, Launch Complex 39 was able to support the initial operating capability.

2. Operational Outcome

While the original concept of flying a fleet of Space Shuttle Orbiters forty times a year (with another twenty flights from Vandenberg AFB) did not materialize, nevertheless, routine access was provided to a much larger astronaut corps (including wider access for multinational flight crews). It was also affordable enough to be sustained for nearly three decades of human space flight (see Fig 8). The nation had demonstrated the ability to design, develop, and operate reusable systems-including the experience of supporting such a system on the ground. The ability to retrieve and return equipment and personnel from space was routinely demonstrated. The ground infrastructure was also created for Shuttle payloads employing biological (both plant and animal), astronomical, and materials science investigations. In short, the enabling ground support (the systems and the workforce know-how) needed to extend human presence to live and work in space was created and demonstrated. This set the stage for the creation and assembly of the International Space Station (ISS). The ground infrastructure to support large scale, multi-element payloads for in-space assembly emerged in KSC's industrial area (the Space Station Processing Facility) as an outcome of the Space Shuttle experience. The stage is now set for an expanded role and the next era for the Spaceport. 


\section{Post-Shuttle/Constellation Ground Infrastructure}

Following the Space Shuttle Columbia accident in 2003, the resulting investigation board recommended a renewed purpose for the U.S. human space flight program. The principle policy documents pertinent to the postShuttle space flight architecture are U.S. President George W. Bush's January 2005 speech outlining the Vision for Space Exploration and the NASA Authorization Act of 2005. The Authorization Act details statutory requirements for transition from the Space Shuttle system to a new system, and to use to the fullest extent possible, the personnel, assets, capabilities and infrastructure of the Space Shuttle Program in the development of the new program. ${ }^{16}$

\section{A. Constellation Ground Infrastructure Mission and Purpose}

An Exploration Systems Architecture Study (ESAS) defined the overall Constellation architecture using two separate launch systems to accomplish ISS sustainment and lunar return. ${ }^{17}$ The launch systems separate crew and cargo delivery functions, including a replacement crew launch vehicle (CLV, later named Ares $I$ ) and a new heavy lift cargo launch vehicle (CaLV, later named Ares V).

Additionally, reusable winged Orbiters would be replaced with a conical spacecraft with a crew capacity of six for missions to the International Space Station (ISS), and a crew of four for the same vehicle configured for missions to the Moon. This crew exploration vehicle (CEV, or later named Orion) is to be launched atop the Ares I. Finally, a lunar surface access module (LSAM, later named Altair) would be the payload for the heavy lift Ares V launcher.

In a lunar mission mode, the Orion-Ares I would be launched separately from a previously-launched Altair-Ares $\mathrm{V}$; the latter would include an earth departure stage (EDS) on which the Altair is attached. The Ares I/Ares V dual launch system would draw from available Space Shuttle elements, such as the Solid Rocket Booster and Launch Complex 39. Following a rendezvous and docking procedure in earth orbit, the combined Orion/Altair/EDS stack would then perform a trans-lunar injection (TLI) burn to the Moon. The Orion spacecraft returns the crew of four via water landing (land landing contingency).

The challenge for the ground systems design team becomes one of building on the existing capabilities. The overall purpose then becomes the transformation of the facilities and infrastructure from the LEO Spaceport of the Space Shuttle/Space Station era into a truly planetary Spaceport that not only supports routine space flights to the Space Station, but can sustain routine human space flights back to the Moon and beyond.

\section{B. Constellation Ground Architectural Approach}

The mobile launch concept was retained given the policy direction and that the mission modes defined in the ESAS require tightly-spaced successive launches with dependable launch pad operations to support two-launch missions to the Moon. Additionally, the Ares space vehicle configurations (Orion-Ares I and Altair-Ares V) require elevated side services, are very tall vehicles, and the only existing functional facilities of these dimensions are located on Complex 39.

As part of the transition from the Space Shuttle program to the new architecture, the Kennedy Space Center (KSC), along with its Constellation element partners, has embarked on a system-by-system assessment throughout the KSC infrastructure. This assessment approach determines the needs of the new architecture, and the compatibility of new requirements, with the existing systems and infrastructures. It then identifies which facilities, facility systems, and distributed services need to be modified, upgraded, designed new, or closed down, because they are no longer needed to support the Constellation program. To this extent some of the major facilities identified for re-use are:

o Vehicle Assembly Building (VAB)

o Launch Pads 39A and 39B

o Launch Control Center (LCC)

o Crawler Transporters

o Solid Rocket Motor Assembly and Remanufacturing Facility (ARF)

o Solid Rocket Motor Rotation, Processing and Surge Facility (RPSF)

o SRB Recovery and Disassembly Facility (Hangar AF)

o Enabling infrastructure necessary to support above facilities such as:

o Industrial power distribution

o Communications networks and services

o Commodity distribution systems for helium, gaseous nitrogen, compressed air, heating ventilation and air conditioning, etc. 


\section{Constellation Ground System Configuration}

In some cases the physical architectural differences are obvious, as in the case of the Vehicle Assembly Building (VAB) access platform configuration, the Mobile Launcher (ML)/transporter configuration and the launch pads. However, trade studies have determined new and unique mobile launchers would be required for both the Orion/Ares I and the Altair/Ares V space vehicles. The fixed structures at Pads 39A and B would be abandoned for a cleaner pad approach. For spacecraft processing, both the Orion and the Altair were envisioned to perform preintegration operations in the Industrial Area, much as was done in the Apollo era. Once again, launch vehicle and spacecraft launch operations would be separated - a departure from the Shuttle Orbiter that combined crew cabin/spacecraft functions and launch vehicle functions. This also freed up certain landing and reusable Orbiter facilities for other space flight opportunities not directly related to Constellation Orion-Ares-Altair operations.

\section{Launch Complex 39 Configuration}

As mentioned, the primary elements of the mobile launch complex (LC39) are retained. Some of the system characteristics are noted below.

Vehicle Assembly Building (VAB) Characteristics—As with the Space Shuttle, the assembly building itself is sound and the only major adaptation to be made is with the extensible platforms. These are to be modified to conform with the outer mold line of the space vehicles and the provision of required facility services to the Mobile Launcher (see Figs. 10 and 11).

For Constellation, trade results have led to the design of all new extensible platforms. A lesson learned from the Apollo/Shuttle platforms is that they were limited in utility due to their loading constraints. The new platforms are designed with over three times the platform loading capability; from less than $1 \mathrm{kNT} / \mathrm{m}^{2}$ ( $\left.20 \mathrm{psf}\right)$ to $3.1 \mathrm{kNT} / \mathrm{m}^{2}$ ( $65 \mathrm{psf})$. This provides greater operational flexibility and improves processing timelines by allowing the operator to stage mobile ground equipment rather than serially impacting extensible platform operations.

Mobile Launcher (ML) Characteristics - Having gone with the mobile launch concept, the launcher becomes the main functional "adapter" between the new space vehicles and the existing ground infrastructure. It not only connects the space vehicles physically, it also is the means for loading the flight system propellants, service fluids, gasses, electrical power, hard line data transfer and also certain rf communications equipment. It connects the stack to the launch pad and to the VAB — and through them to the Launch and Mission Control Centers.

The Orion/Ares I Mobile Launcher (ML-1) is composed of a Mobile Launcher Base (MLB) and a Mobile Launcher Tower (MLT). The launcher's base is all new and does not reuse the MLP of the Space Shuttle. It connects through cables, fluid lines, and ducts to the VAB and the Pad. The MLT has two high speed elevators, a dedicated crew access arm, four tilt-up T-0 umbilicals, and two swing-type umbilicals. A new design challenge is the addition of a cold helium propellant loading system for the Upper Stage. Also added is a launch mount adapter, which is required due to complexities in the extension of the first stage nozzle exit cone relative to the Shuttle SRB aft skirt. The removable launch mount may also provide future design and operations flexibility. The more "adapters" put into the system, the easier it is to accommodate new designs into existing infrastructure.

Crawler Transporter (C/T) Characteristics - In keeping with the reuse approach, the new Orion-Ares I configuration had to make sure that the present capacity of the crawlers would not be compromised with the design of the ML. Design trades to this point have taken care to constrain the new design from growing beyond existing crawler design margins. The Orion-Ares I ML design has been successfully achieved through good systems engineering practices and through constant vigilance of the space and weight allocations to the different systems that make up the ML. However, for the larger Ares $\mathrm{V}$ and its mobile launcher, ongoing trades are addressing an increased capacity of the existing tracked crawlers versus other replacement designs.

Launch Control Center (LCC) Characteristics-Command, control, and communication with the flight and ground systems is still accomplished through a centralized, four-story control center. However, the Shuttle Launch Processing System (LPS) is being replaced with a more modern Launch Control System (LCS) for outfitting in the Firing Rooms.

Launch Pad Characteristics-The launch pads will eventually eliminate the free-standing Fixed Service Structure (FSS) and Rotating Service Structure (RSS), as these functions are now incorporated in the Mobile Launcher design (see Fig. 12).

Also envisioned is a different emergency egress system that employs a rail-based approach, rather than use of highly-elevated slide wires.

Additionally, the fixed hypergol fuel farms are not required, since the operational concept is to use mobile equipment staged on the ML for toxic propellant loading operations at the Pad (spacecraft hypergolic loading is envisioned to be performed offline in the KSC Industrial Area). 
In some cases the existing Shuttle system has plenty of performance and capability while in others the system needs to be analyzed for requirement compliance with the present Constellation requirements; case in point is the Pad B Environmental Control System (ECS). In the Shuttle configuration, up to four supply channels are needed to provide controlled purges to different areas of the vehicle and the Pad, such as: the Orbiter payload bay, the Orbiter aft compartment, the Orbiter crew compartment, and the Pad Payload Change-out Room (PCR). The Constellation requirements for Orion-Ares I, however, are less restrictive in terms of the number areas to supply. However, since the Constellation architecture requires a longer travel length for purge flow over the system (the Ares vehicles are much taller) a special test was run with the Shuttle ECS system and the flow velocity and pressure characteristics were measured to determine total system margins for a new design.

In a similar fashion, the Pad cryogenic storage and transfer systems have been analyzed to be adequate for Ares I Upper Stage propellant loading operations. Therefore, the storage spheres are retained. The cryogenic transfer lines and supporting equipment are also largely retained.

One major new addition to the Pad is the erection of the new lightning protection system. This new system consists of three $180 \mathrm{~m}(587 \mathrm{ft})$ towers that will provide enhanced protection from lightning strikes to the vehicle. Since the Constellation vehicle/ML combinations are so much taller than the present Shuttle, the legacy lightning protection approach (a single mast on the nearby service structure) would not provide the desired level of protection in the Florida environment. The new towers will provide a cage-like protection to meet the need.

In summary, every effort is being made to utilize as much of the existing Pad infrastructure and systems to obtain the best possible solution in support of the Constellation program.

\section{KSC Industrial Area Configuration}

The Industrial Area of NASA's Kennedy Space Center also contributes to the Constellation Program.

Operations and Checkout (O\&C) Building Characteristics - The O\&C building, once used for offline Apollo spacecraft processing and Shuttle Spacelab and payload processing, is undergoing renewal. The O\&C high bay and low bay will accommodate final assembly of the Orion spacecraft prior to delivery to NASA for propellant loading and ordnance installation operations before transporting to the VAB. The various spacecraft modules that make up the Orion spacecraft, like Apollo, are to arrive at the O\&C for checkout, pre-stacking servicing, and element mating. This includes checkout and mating of the Orion Crew Module and the encapsulated Service Module with its Spacecraft Adapter (or SA). There is currently no planned use for the altitude chambers, but are retained in the facility.

Offline Industrial Area Hazardous Facility Characteristics-The Hypergolic Maintenance Facility (HMF) of the Shuttle era will not be reused for the Constellation Program. However, a hazardous propellant and ordnance installation facility is required for the Orion and Altair spacecraft. The Multipurpose Payload Processing Facility, or MPPF, will be expanded to accommodate the Orion spacecraft for both pre-flight propellant servicing and for postflight Crew Module de-servicing prior to delivery to the manufacturing/final assembly contractor in the O\&C.

Launch Equipment Test Facility (LETF) Characteristics - Once again, to facilitate risk reductions in highly critical T-0 tilt-up umbilical assemblies (TUAs), swing arm umbilicals, and the crew access arm, the previous investment in the LETF infrastructure is being employed.

\section{Projected Constellation Ground Infrastructure Outcome}

\section{Projected Design and Development Outcome}

By leveraging the Apollo and Space Shuttle experience in ground system design and development, reasonable maintenance and upgrades are projected to help shorten the gap between Space Shuttle and Constellation operations, reduce the up-front expenditure, and get us back to the Moon and beyond (see Fig 13).

\section{Projected Operational Outcome}

The Orion-Ares I space vehicles and the supporting mobile launch infrastructure is projected to support five or six flights per year on a single string of ground infrastructure assets; i.e., one ML, one VAB high bay, and one launch pad. Additionally, enough existing architecture is left over to adapt much of it to the larger Altair-Ares V, without the lead time and up-front investment of designing and constructing from scratch. The outcome is expected to produce a renewed ground support infrastructure that has the capability of not only launching to and from low earth orbit, but also has the capability of extending the human presence beyond low earth orbit—back to the Moon and beyond. 


\section{Summary}

The evolutionary basis for Kennedy Space Center's mobile launch architecture has been described. The new Constellation architecture, adapted into the existing mobile launch ground infrastructure, is projected to enable more efficient launch processing for a given set of ground assets, thus avoiding more expensive ground infrastructure investments than otherwise might be required. 


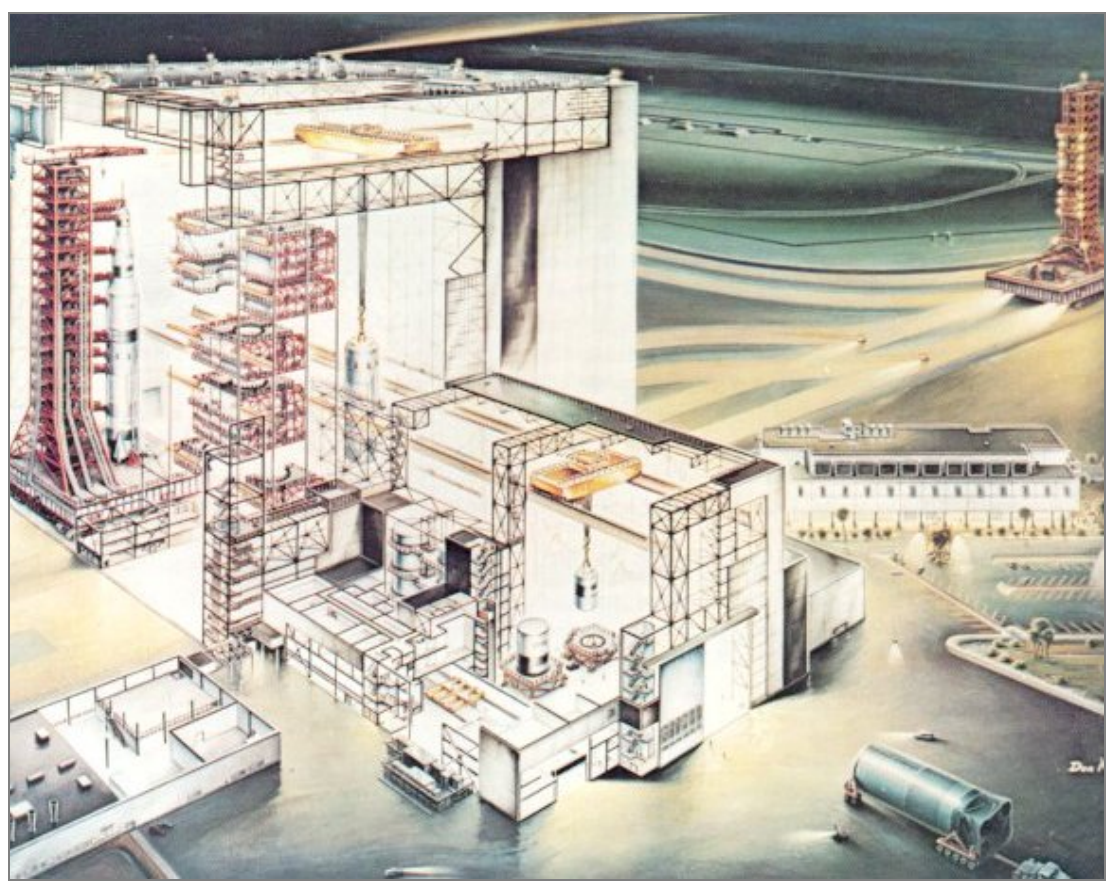

Figure 1. Vehicle Assembly Building. Also depicts mobile launchers and extensible work platforms.

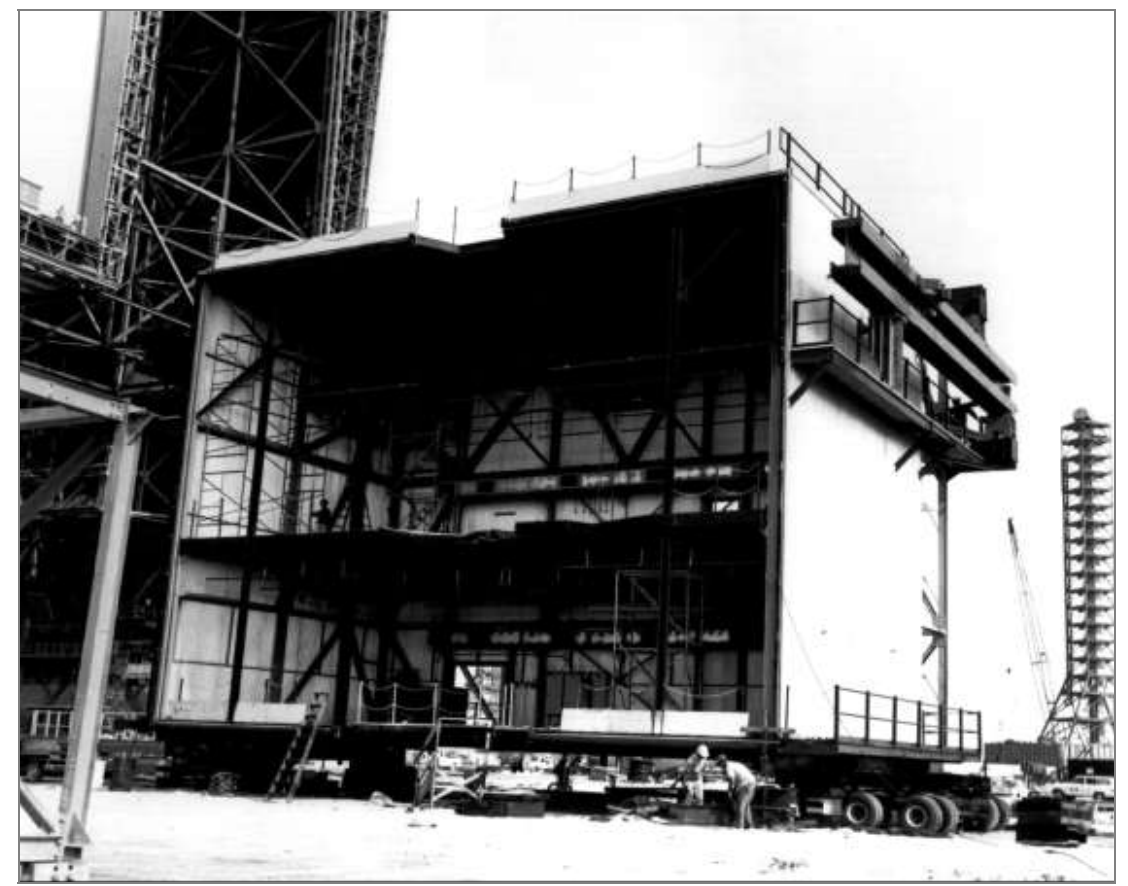

Figure 2. VAB Extensible Platform under Construction. Each platform was designed to translate horizontally to wrap around the space vehicle as it was "stacked" and prepared prior to rollout to the launch pad. 


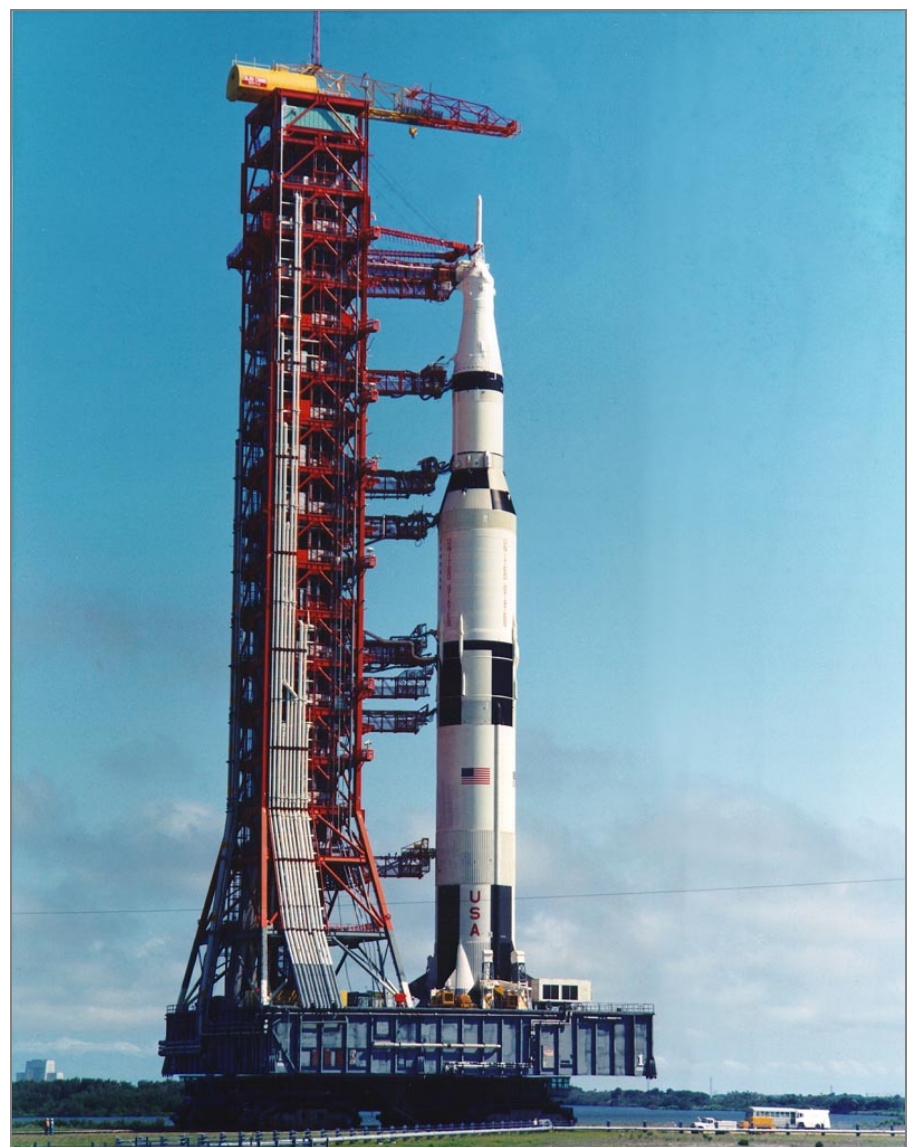

Figure 3. Mobile Launcher Umbilical/Access Arms. This photo shows the numerous swing-type access/umbilical arms. There were nine total on the Apollo-Saturn V ML. There were three MLs for the Apollo Program.

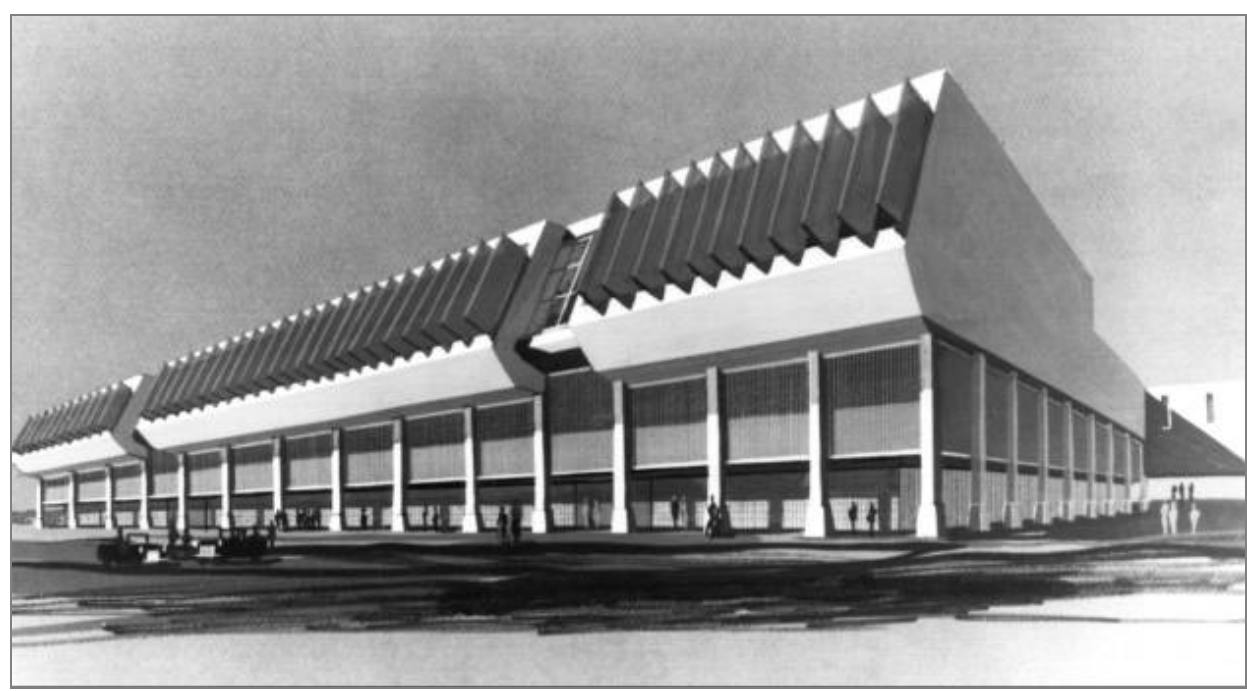

Figure 4. Launch Control Center. This facility consolidated numerous functions into a central, remote facility that alleviated the need for difficult to design bunkers and blockhouses within the blast danger area. 


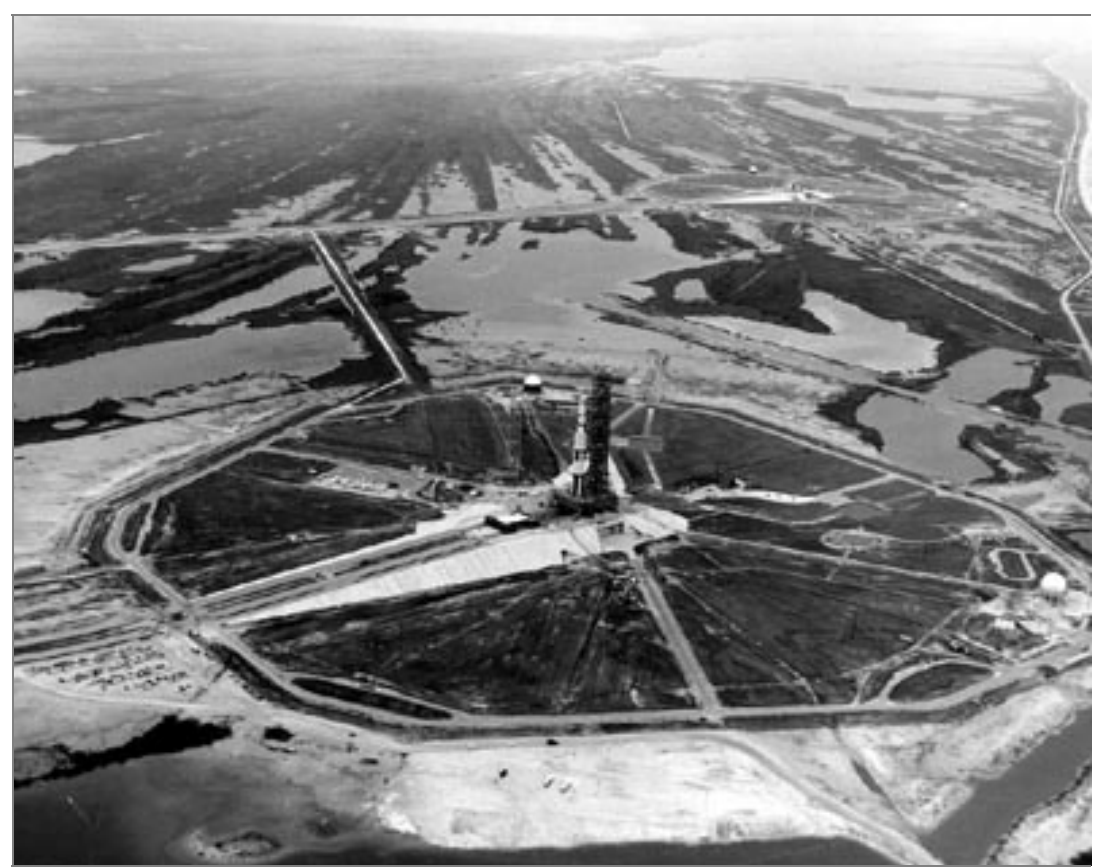

Figure 5. Launch Pad 39. Depicts the propellant storage spheres, the Pad apron, perimeter road, and the Apollo-Saturn V-Mobile Launcher stack.

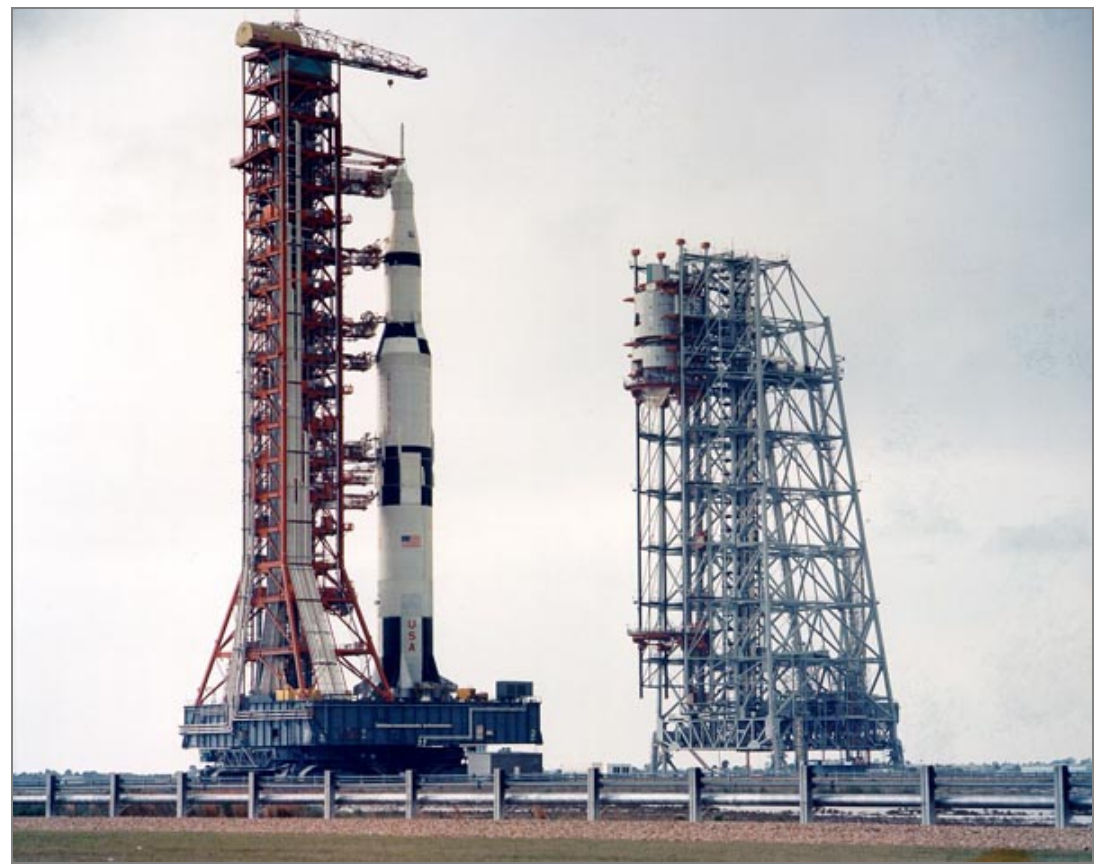

Figure 6. Mobile Service Structure (MSS). In this photo the Mobile Launcher, carrying an Apollo-Saturn V space vehicle, passes the MSS at its Park site midway to the launch pad on the crawler way. The MSS on the right was carried by the crawler to the launch point once the ML/Apollo-Saturn stack arrived at the Pad. Toxic propellant spacecraft servicing and final ordnance operations were conducted from the structure by launch site operations personnel.

American Institute of Aeronautics and Astronautics 092407 



Figure 7. The Skylab/ASTP Evolved Launch Configuration. Mobile Launcher 1 was modified to accommodate the Saturn 1B vehicle for manned earth orbiting missions.

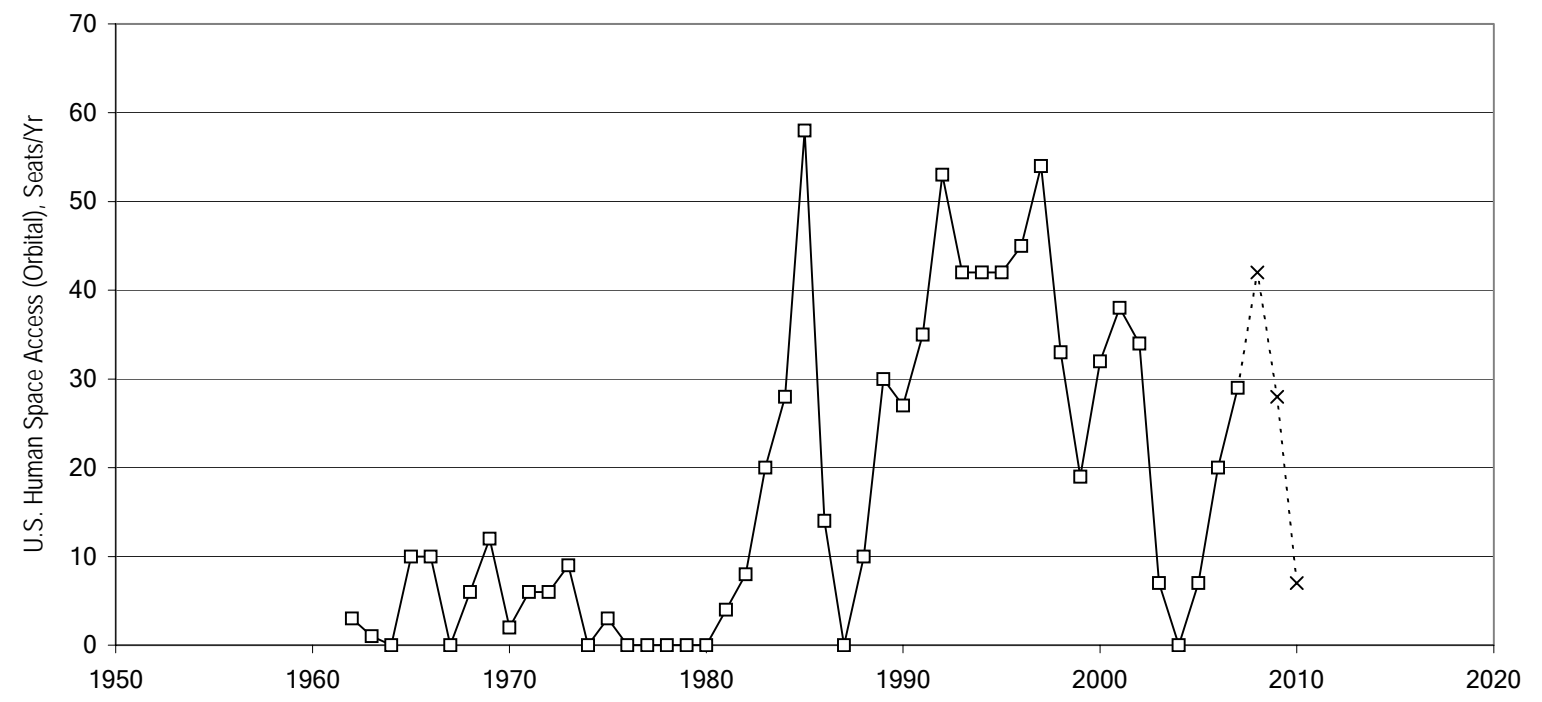

Figure 8. Plot of U.S. Human Orbital Space Access (1962 through 2004). Graph shows the clear distinction between pre-Shuttle era capability (before 1981) and the Space Shuttle era (post 1981). The plot also shows that while the Shuttle system has operated during this period, the outcome has nonetheless been difficult to sustain through the loss of two Orbiters and their flight crews. 

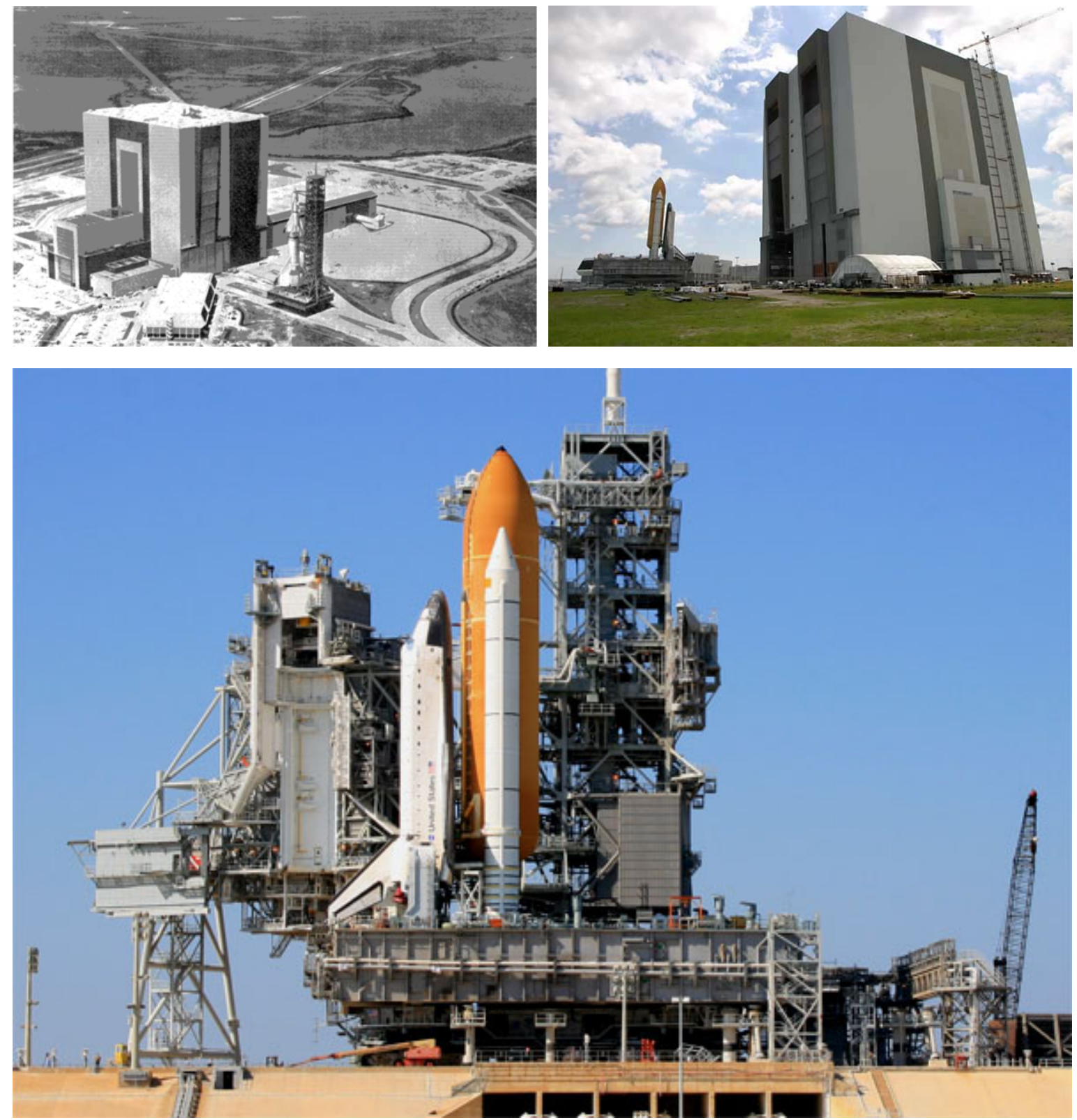

Figure 9. Space Shuttle Launch Structures. (Right) Early two-stage, fully reusable Shuttle ground system architectural concept using Saturn-era Mobile Launcher and umbilical tower. (Left) Actual Shuttle rollout configuration. (Bottom) Space Shuttle launch pad configuration with fixed Pad structures. 


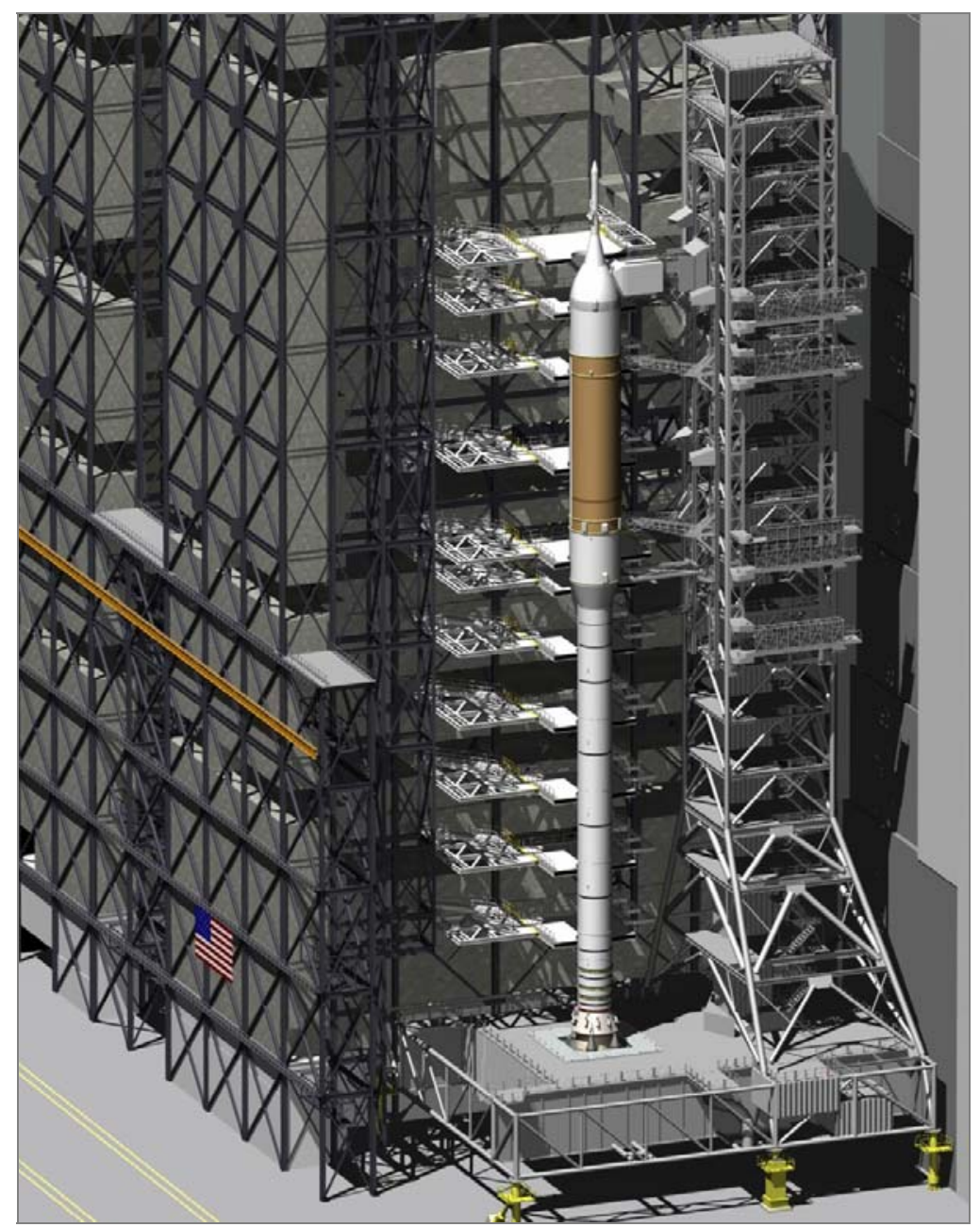

Figure 10. Orion-Ares I Launch Vehicle Assembly. Illustration depicts the space vehicle on its Mobile Launcher in the VAB high bay with extensible platforms in the retracted position.

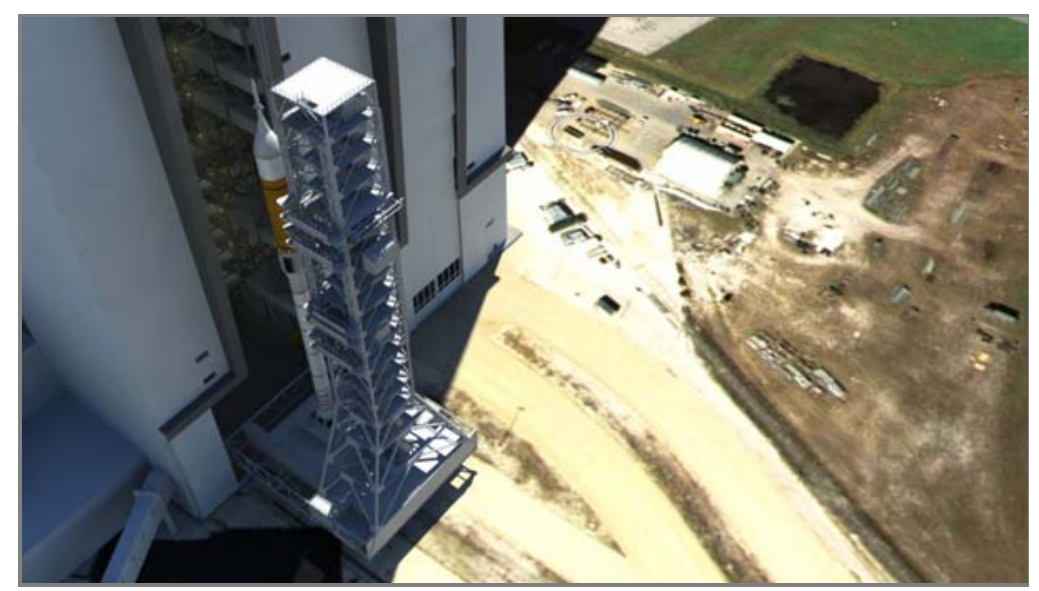

Figure 11. Orion-Ares I VAB Rollout. Graphic depicts the space vehicle/Mobile Launcher stack as it rolls out on the Crawler Transporter and travels over 5 kilometers to Launch Pad 39B. Transfer operation takes approximately one work shift to perform from first motion to ML hard down on Pad support pedestals.

American Institute of Aeronautics and Astronautics 092407 


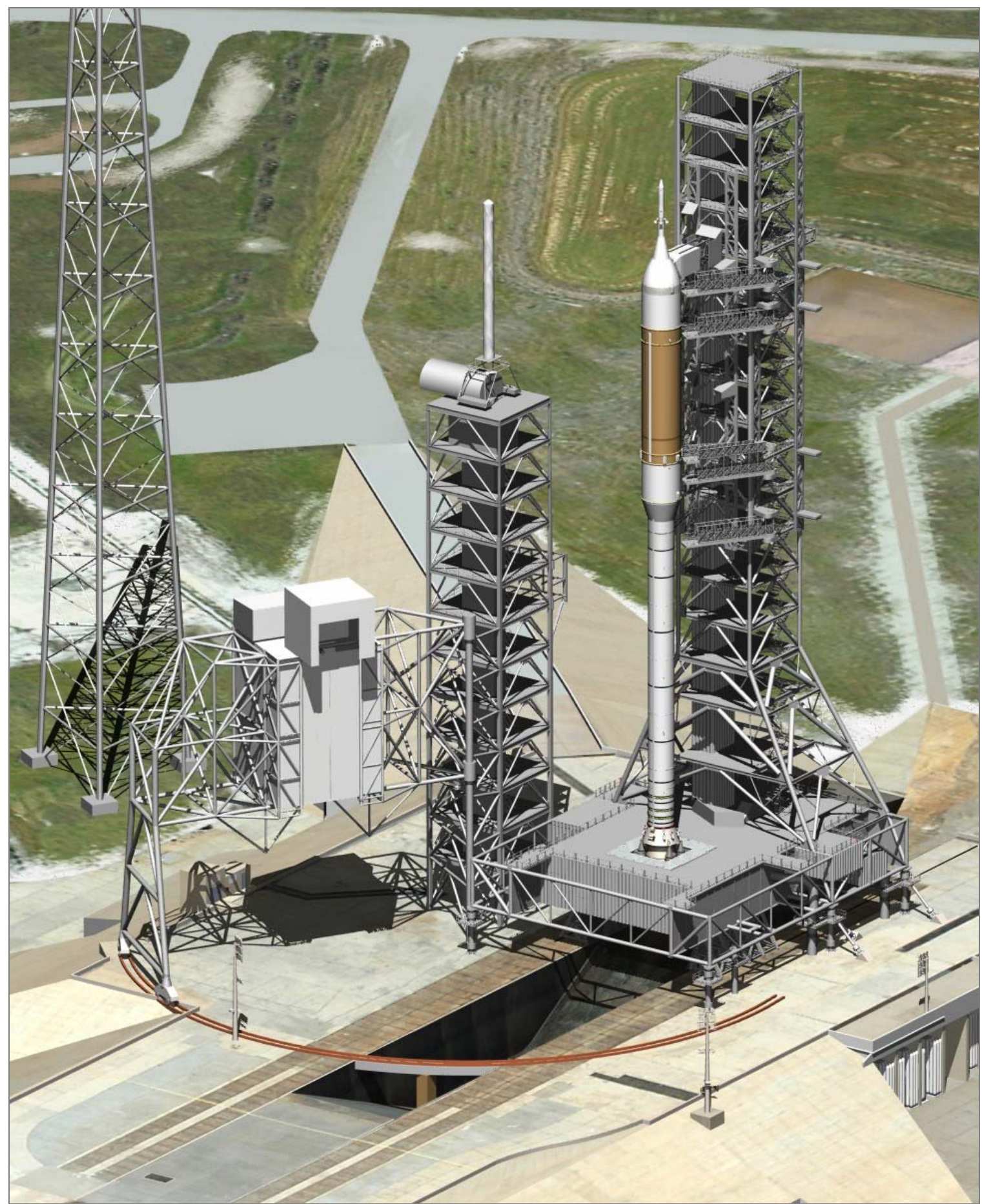

Figure 12. Orion-Ares I launch Vehicle at the Pad. (Shows legacy Shuttle structures prior to demolition). 

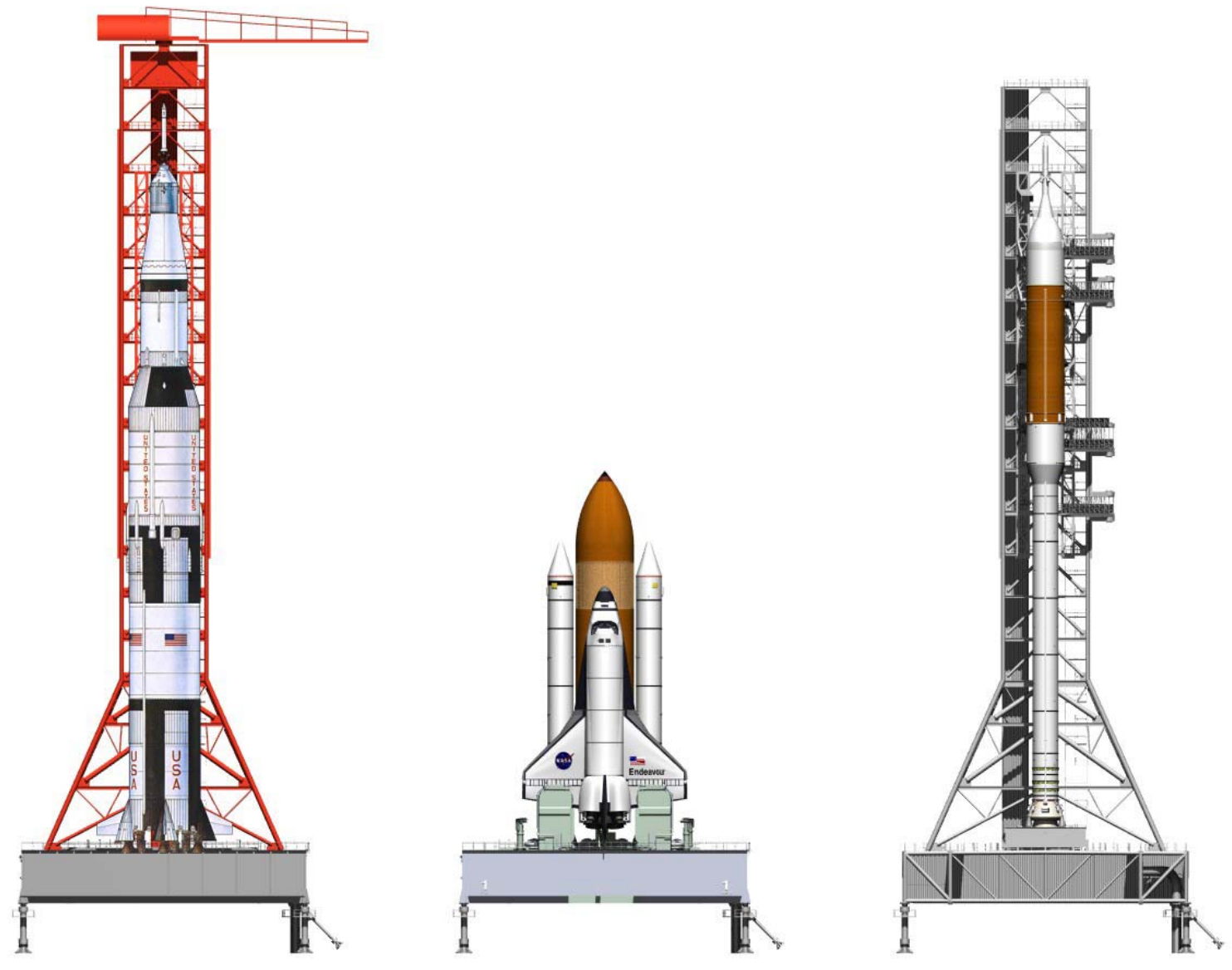

Figure 13. Evolutionary Comparison of NASA Mobile Launchers (Apollo-Saturn V/Shuttle/Orion-Ares I). 


\section{References}

${ }^{1}$ Stanley, D., et al, “NASA’s Exploration Systems Architecture Study,” NASA TM-2005-214062, November, 2005.

${ }^{2}$ National Aeronautics and Space Administration Authorization Act of 2005 [S.1281], Public Law 155, Sect. 502(a), 109 ${ }^{\text {th }}$ Cong., 1st sess., 30 December 2005.

${ }^{3}$ Griffin, Michael D., Administrator, National Aeronautics and Space Administration; speech given to the Space Transportation Association, Washington, D.C, January, 2008.

${ }^{4}$ Benson, C. D., Faherty, W. B., Moonport: A History of Apollo Launch Facilities and Operations, pp.65-7, NASA SP-4204, Washington, D.C., 1978.

${ }^{5}$ Ibid. Moonport, p. 80.

${ }^{6}$ Ibid. Moonport, p. 73.

${ }^{7}$ Debus, Kurt H., Dr., and Davis, Leighton I., Maj. Gen. (USAF), “Joint Report on Facilities and Resources Required at Launch Site to Support NASA Manned Lunar Landing Program (Debus-Davis Report),” NASA KSC Archives, 31 July 1961.

${ }^{8}$ Seamans, Robert A., Project Apollo-The Tough Decisions, Monographs in Aerospace History, No. 37, NASA SP-2005-4537; Washington, D.C., 2005.

${ }^{9}$ Moonport, p. 73.

10 Debus, Dr. Kurt H., “Novel High Efficiency Facilities for Assembly, Test and Launch of Space Vehicles,” for presentation to The German Rocket Society, Koblenz, Germany, September 1962. Debus Papers, KSC Archives.

${ }^{11}$ Moonport, p. 74.

12 Compton, W. David, Where No Man Has Gone Before: A History of Apollo Lunar Exploration Missions, NASA SP-4214; Washington, D. C., 1989.

${ }^{13}$ Buchanan, D. D., “Space Shuttle Launch Operations Center Study,” NASA TR-1078-1; KSC, Florida, December 1, 1971.

${ }^{14}$ Lipartito, K., Butler O. R., A History of the Kennedy Space Center, pp. 223-4, NASA Kennedy Space Center; University Press of Florida, Gainesville, Florida, 2007.

${ }^{15}$ It should be noted that there were trade studies early in the Shuttle era for propellant supply upgrades when the Shuttle launch rate was to accelerate toward the objective of a flight every two weeks. Since LOX and LH2 resupply between flights was performed by numerous tanker trucks, this approach could become both expensive and time consuming at high flight rates. Trades for design of on-site propellant production capabilities were accomplished, but never progressed beyond study phase, as the flight rates never reached beyond eight (8) per year; well within the viability of off-site supplied cryogenics.

${ }^{16}$ NASA Authorization Act, 2005.

${ }^{17}$ Stanley, D., et al, “NASA’s Exploration Systems Architecture Study,” NASA TM-2005-214062, November, 2005. 